\title{
Metformin and low levels of thyroid-stimulating hormone in patients with type 2 diabetes mellitus
}

\author{
Jean-Pascal Fournier MD PhD, Hui Yin MSc, Oriana Hoi Yun Yu MD MSc, Laurent Azoulay PhD
}

Competing interests: None declared.

This article has been peer reviewed.

\section{Correspondence to:} Laurent Azoulay, laurent.azoulay@mcgill.ca

CMAJ 2014. DOI: 10.1503 /cmaj.140688

\begin{abstract}
Background: Small cross-sectional studies have suggested that metformin, a first-line oral hypoglycemic agent, may lower thyroid-stimulating hormone (TSH) levels. Our objective was to determine whether the use of metformin monotherapy, when compared with sulfonylurea monotherapy, is associated with an increased risk of low TSH levels $(<0.4 \mathrm{mIU} / \mathrm{L})$ in patients with type 2 diabetes mellitus.
\end{abstract}

Methods: Using the Clinical Practice Research Datalink, we identified patients who began receiving metformin or sulfonylurea monotherapy between Jan. 1, 1988, and Dec. 31, 2012. We assembled 2 subcohorts of patients with treated hypothyroidism or euthyroidism, and followed them until Mar. 31, 2013. We used Cox proportional hazards models to evaluate the association of low TSH levels with metformin monotherapy, compared with sulfonylurea monotherapy, in each subcohort.

Results: A total of 5689 patients with treated hypothyroidism and 59937 euthyroid patients were included in the subcohorts. Among patients with treated hypothyroidism, 495 events of low TSH levels were observed during follow-up (incidence rate 119.7/1000 personyears). In the euthyroid group, 322 events of low TSH levels were observed (incidence rate 4.5/1000 person-years). Compared with sulfonylurea monotherapy, metformin monotherapy was associated with a $55 \%$ increased risk of low TSH levels in patients with treated hypothyroidism (incidence rate 79.5/1000 person-years v. $125.2 / 1000$ person-years, adjusted hazard ratio [HR] 1.55, 95\% confidence interval [Cl] 1.092.20), with the highest risk in the 90-180 days after initiation (adjusted HR 2.30, 95\% Cl 1.005.29). No association was observed in euthyroid patients (adjusted HR 0.97, 95\% Cl 0.69-1.36).

Interpretation: In this longitudinal populationbased study, metformin use was associated with an increased incidence of low TSH levels in patients with treated hypothyroidism, but not in euthyroid patients. The clinical consequences of this need further investigation.
$\mathrm{M}$ etformin, a first-line oral hypoglycemic agent for the treatment of type 2 diabetes mellitus, improves hepatic insulin resistance and reduces glucose production. ${ }^{1}$ However, despite its excellent safety profile, ${ }^{2}$ studies have suggested that its use may lower thyroid-stimulating hormone (TSH) levels in patients with diabetes and hypothyroidism. ${ }^{3-9}$ In some studies, the use of metformin was associated with reductions in TSH levels below the reference range, ${ }^{4-7}$ potentially exposing patients to the harmful consequences of subclinical hyperthyroidism (e.g., cardiovascular conditions and fractures ${ }^{10}$ ). In contrast, metformin was not associated with changes to TSH levels in euthyroid patients. ${ }^{11}$ Given the methodologic shortcomings of the few studies conducted to date (i.e., small samples, cross-sectional designs and no active comparator), it remains uncertain whether the use of metformin is associated with an increased risk of low TSH levels in patients with hypothyroidism or euthyroidism and type 2 diabetes.
Given the widespread use of metformin in patients with type 2 diabetes and the potential negative consequences of low TSH levels, there is a need to assess the incidence and magnitude of this biochemical event in the natural setting of clinical practice. Thus, the objective of this large population-based study was to determine whether the use of metformin monotherapy, when compared with sulfonylurea monotherapy, is associated with an increased risk of low TSH levels $(<0.4 \mathrm{mIU} / \mathrm{L})$ in patients with treated hypothyroidism or euthyroidism and type 2 diabetes.

\section{Methods}

\section{Data source}

We used the Clinical Practice Research Datalink (CPRD) to conduct this study. Established in 1987, the CPRD includes data on more than 13 million patients from over 680 general practices in the United Kingdom. It records informa- 
tion on diagnoses, referrals, lifestyle habits, anthropometric measurements (e.g., body mass index) and prescriptions issued by general practitioners. The CPRD is regularly audited and has been shown to be highly valid..$^{12,13}$

The study protocol was approved by the Independent Scientific Advisory Committee of the CPRD (protocol 14040) and by the Research Ethics Committee of the Jewish General Hospital in Montréal.

\section{Study population}

We assembled a base cohort of patients at least 40 years of age who began receiving either metformin or sulfonylurea monotherapy between Jan. 1, 1988, and Dec. 31, 2012. Patients were required to have at least 1 year of medical history in the CPRD before the first metformin and sulfonylurea prescriptions, with no evidence of other antidiabetic drugs being prescribed at any time before these first prescriptions. Thus, cohort entry was the date of the first-ever prescriptions for metformin and sulfonylureas during the study period. We excluded patients with a history of cancer (other than nonmelanoma skin cancer) and pituitary disorders at any time before cohort entry. We also excluded women with a diagnosis of polycystic ovary syndrome or gestational diabetes at any time before cohort entry, or pregnancy in the year before cohort entry. Finally, for the purposes of this study, the cohort was restricted to patients whose TSH levels had been measured at least once in the year before cohort entry.

Using the base cohort, we assembled 2 subcohorts of patients with treated hypothyroidism and euthyroidism. Patients with treated hypothyroidism were identified by the presence of at least 2 prescriptions for levothyroxine. They were excluded if they were receiving concurrent treatment with antithyroid drugs, or if they had TSH levels outside the reference range (0.4$\left.4.5 \mathrm{mIU} / \mathrm{L}^{14}\right)$ in the year before cohort entry. Euthyroid patients were identified by exclusion of those with records of thyroid-related disorders, drugs or procedures, and of those with TSH levels outside the reference range (0.4-4.5 mIU/ $\mathrm{L}^{14}$ ) in the year before cohort entry.

All patients were followed from cohort entry until a first TSH measurement below $0.4 \mathrm{mIU} / \mathrm{L}$, the initiation (in euthyroid patients) or dosage modification (increase or decrease) of thyroidrelated drugs, a TSH measurement above $4.5 \mathrm{mIU} / \mathrm{L}$ (such an increase might result in the initiation or intensification of levothyroxine, leading to subsequent normal TSH levels ${ }^{15}$ ), death from any cause, end of registration with the general practice or end of the study period (Mar. 31, 2013), whichever occurred first.

\section{Exposure assessment}

Within each subcohort, we conducted an astreated analysis. For this analysis, patients were considered continuously exposed to metformin or sulfonylureas if they received successive overlapping prescriptions, allowing for a 30-day grace period between successive nonoverlapping prescriptions. Thus, patients not receiving a subsequent prescription were censored at the end of the 30-day grace period, as were patients who added-on or switched to any other antidiabetic agent. Patients receiving metformin monotherapy were compared with patients receiving sulfonylurea monotherapy to minimize confounding by indication, because the latter can be used as a first-line treatment for type 2 diabetes. ${ }^{16}$

\section{Statistical analysis}

We used descriptive statistics to summarize the characteristics of patients receiving metformin and sulfonylurea monotherapy, separately for each subcohort. Crude incidence rates of low TSH levels $(<0.4 \mathrm{mIU} / \mathrm{L})$, with $95 \%$ confidence intervals (CIs) based on the Poisson distribution, were calculated for each exposure group.

Kaplan-Meier curves were plotted for the cumulative incidence of low TSH levels for each exposure group, stratified by subcohort. For each subcohort, we used Cox proportional hazards models to estimate crude and adjusted hazard ratios (HRs) with 95\% CIs for the incidence of low TSH levels associated with the use of metformin monotherapy, compared with sulfonylurea monotherapy. The following potential confounders, which were considered a priori, were included in the model: age, sex, calendar year of cohort entry, body mass index, smoking status, excessive alcohol use (i.e., alcohol-related disorders such as alcoholism, alcoholic cirrhosis, alcoholic hepatitis and hepatic failure), hemoglobin $A_{1 C}$ level (last measure before cohort entry), and use of lithium, amiodarone, glucocorticoids and dopamine agonists ${ }^{17}$ (measured in the year before cohort entry). Dopamine agonists were not included in the final model because of their low prevalence and instability in the models. Variables with missing information were coded with an "unknown" category.

In secondary analyses, we assessed whether there was a duration-response relation between the use of metformin and the risk of low TSH levels in each subcohort. Using time-dependent Cox proportional hazards models, we estimated HRs for 3 categories of duration of use $(<90 \mathrm{~d}$, 90-180 d, > $180 \mathrm{~d}$ ). We also estimated HRs for the association between metformin and the risk of suppressed TSH levels $\left(<0.1 \mathrm{mIU} / \mathrm{L}^{14}\right)$. It was not possible to assess thyroxine and triiodothyro- 
nine levels, given their low testing rates $(0.037$ and 0.013 tests/1000 person-years for patients with treated hypothyroidism and euthyroidism, respectively).

We performed 7 sensitivity analyses. First, we assessed residual confounding by fitting the outcome models with high-dimensional propensity score deciles ${ }^{18}$ (for additional details, see Appendix 1, available at www.cmaj.ca/lookup/suppl /doi:10.1503/cmaj.140688/-/DC1). Second, we conducted an intention-to-treat analysis, in which the initial treatment was carried forward until a maximum of 2 years. Third, we repeated the primary analysis after excluding first-generation sulfonylureas because they have been associated with an increased risk of hypothyroidism in earlier studies. ${ }^{19,20}$ Fourth, to minimize potential residual confounding, ${ }^{21}$ we further restricted the cohort with treated hypothyroidism to patients who, in the year before cohort entry, had stable doses of levothyroxine (i.e., last 2 prescriptions at the same daily dosage) and whose last $2 \mathrm{TSH}$ measurements were within the reference range (0.4-4.5 mIU/L) and within $\pm 0.5 \mathrm{mIU} / \mathrm{L}$ of each other. Fifth, patients were additionally censored at the time of a new cancer diagnosis, pregnancy or infection (using antibiotics as a proxy), because these conditions may result in transient fluctuation of TSH levels. Sixth, cohort entry was moved to the 30 days after the first prescription of metformin and sulfonylureas to minimize possible misclassifications related to the situation where the actual TSH measurement was recorded in the database after cohort entry, and to account

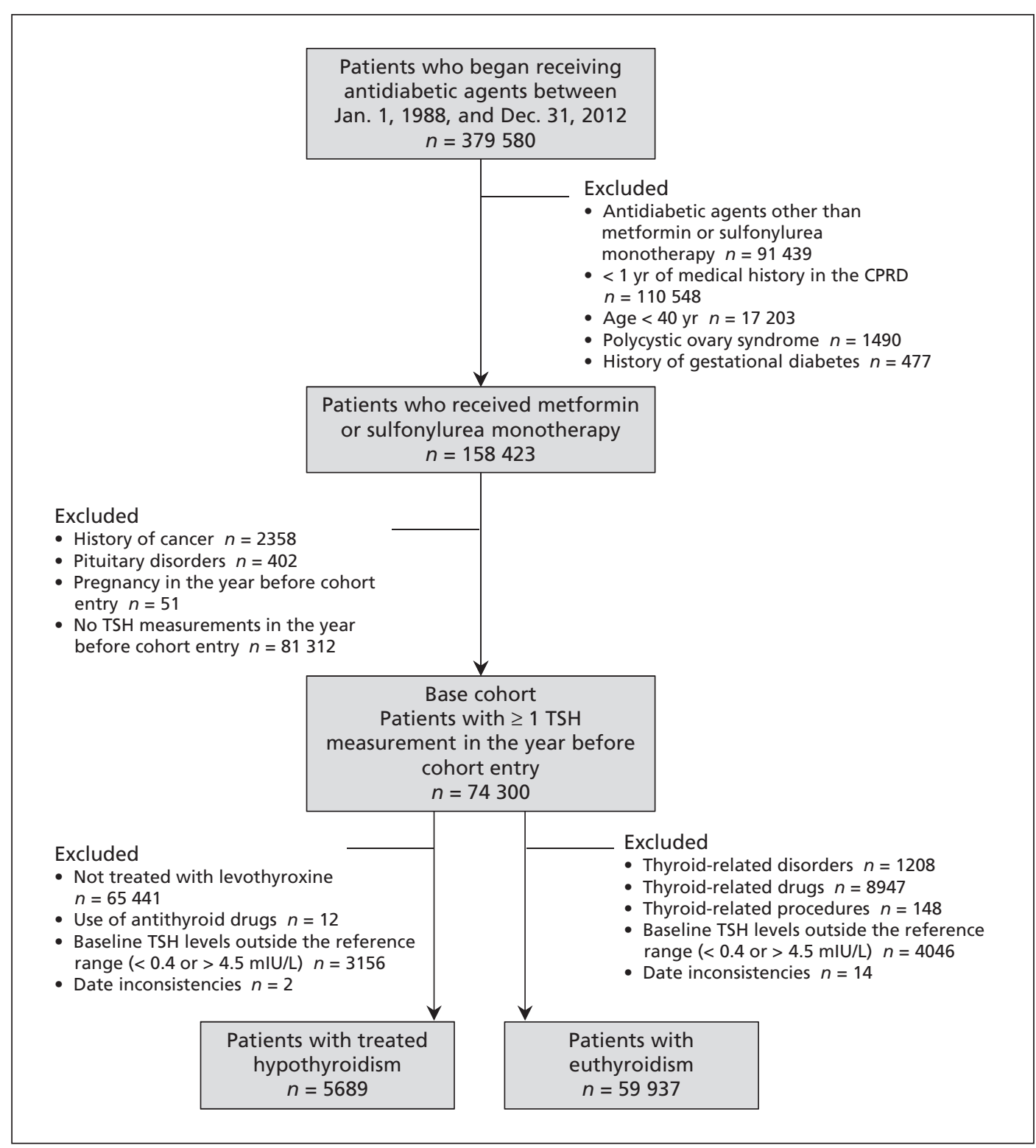

Figure 1: Inclusion of patients in the study. CPRD = Clinical Practice Research Datalink, TSH = thyroidstimulating hormone. 
for a minimum 30-day latency period between treatment initiation and outcome. Finally, to assess the effect of missing TSH measurements that may have been measured but not recorded in the database during follow-up, we censored patients with no TSH measurements in the year after cohort entry, as well as patients with no repeat TSH measurements within 1 year of each other. All analyses were conducted using SAS version 9.3 (SAS Institute).

Table 1: Baseline characteristics of patients with treated hypothyroidism or euthyroidism and type 2 diabetes who started antidiabetic treatment with either metformin or sulfonylurea monotherapy

\begin{tabular}{|c|c|c|c|c|}
\hline \multirow[b]{3}{*}{ Characteristic } & \multicolumn{4}{|c|}{ No. $(\%)$ of patients* } \\
\hline & \multicolumn{2}{|c|}{$\begin{array}{c}\text { Hypothyroidism } \\
n=5689\end{array}$} & \multicolumn{2}{|c|}{$\begin{array}{c}\text { Euthyroidism } \\
n=59937\end{array}$} \\
\hline & $\begin{array}{l}\text { Metformin } \\
n=4927\end{array}$ & $\begin{array}{c}\text { Sulfonylurea } \\
n=762\end{array}$ & $\begin{array}{l}\text { Metformin } \\
n=51957\end{array}$ & $\begin{array}{c}\text { Sulfonylurea } \\
n=7980\end{array}$ \\
\hline Age, yr, mean \pm SD & $66.2(11.4)$ & $72.7(11.6)$ & $62.2(11.5)$ & $67.7(12.6)$ \\
\hline Male sex & $1026(20.8)$ & $168(22.1)$ & $30169(58.1)$ & $4609(57.8)$ \\
\hline \multicolumn{5}{|l|}{ Body mass index } \\
\hline$<25$ & $395 \quad(8.0)$ & $227(29.8)$ & $4757 \quad(9.2)$ & $2831(35.5)$ \\
\hline $25-29.9$ & $1297(26.3)$ & $261(34.3)$ & $16131(31.1)$ & $2908(36.4)$ \\
\hline $30-39.9$ & $2450(49.7)$ & $211(27.7)$ & 24817 (47.8) & $1781(22.3)$ \\
\hline$\geq 40$ & $740(15.0)$ & 31 (4.1) & $5842(11.2)$ & $224(2.8)$ \\
\hline Unknown & $45 \quad(0.9)$ & $32(4.2)$ & $410 \quad(0.8)$ & $236(3.0)$ \\
\hline \multicolumn{5}{|l|}{ Smoking status } \\
\hline Current & $622(12.6)$ & $86(11.3)$ & $9388(18.1)$ & $1546(19.4)$ \\
\hline Former & $2156(43.8)$ & $317(41.6)$ & $22344(43.0)$ & $2972(37.2)$ \\
\hline Never & $2099(42.6)$ & $322(42.3)$ & 19671 (37.9) & $3128(39.2)$ \\
\hline Unknown & $50 \quad(1.0)$ & 37 (4.9) & $554 \quad(1.1)$ & $334(4.2)$ \\
\hline Excessive alcohol uset & 472 (9.6) & $66(8.7)$ & $6305(12.1)$ & $812(10.2)$ \\
\hline Diabetes duration, yr, mean \pm SD $\ddagger$ & $2.5 \quad(3.5)$ & $2.5(3.6)$ & $2.3 \quad(3.4)$ & $2.1(3.3)$ \\
\hline \multicolumn{5}{|l|}{ Hemoglobin $A_{1} \varsigma \S$} \\
\hline$<6.5 \%$ & $220 \quad(4.5)$ & $22(2.9)$ & $2276 \quad(4.4)$ & $318(4.0)$ \\
\hline $6.5-7.4 \%$ & $906(18.4)$ & $56(7.4)$ & 8607 (16.6) & $733(9.2)$ \\
\hline $7.5-8.9 \%$ & $1693(34.4)$ & $216(28.4)$ & 17604 (33.9) & $1988(24.9)$ \\
\hline$\geq 9 \%$ & $953(19.3)$ & $183(24.0)$ & $13457(25.9)$ & $2396(30.0)$ \\
\hline Unknown & $1155(23.4)$ & $285(37.4)$ & $10013(19.3)$ & $2545(31.9)$ \\
\hline Amiodaroneף & $54 \quad(1.1)$ & $23(3.0)$ & $237 \quad(0.5)$ & $82(1.0)$ \\
\hline Lithiumף & $57 \quad(1.2)$ & $<5+\dagger$ & $226 \quad(0.4)$ & $37(0.5)$ \\
\hline Glucocorticoidsף & $687(13.9)$ & $176(23.1)$ & $4999 \quad(9.6)$ & $1174(14.7)$ \\
\hline Dopamine agonists & $23(0.5)$ & $<5 † \dagger$ & $143 \quad(0.3)$ & $21(0.3)$ \\
\hline Baseline TSH level, mIU/L, mean \pm SD§ & $2.1 \quad(1.9)$ & $1.9(2.0)$ & $1.8 \quad(1.2)$ & $1.7(1.2)$ \\
\hline \multicolumn{5}{|l|}{ Levothyroxine } \\
\hline Years since initiation, mean \pm SD & $7.1 \quad(5.1)$ & $6.8(5.0)$ & - & - \\
\hline Dose, $\mu \mathrm{g}$, mean $\pm \mathrm{SD} \S$ & $99.4(49.5)$ & $93.7(47.3)$ & - & - \\
\hline Dose/weight, $\mu \mathrm{g} / \mathrm{kg}$, mean $\pm \mathrm{SD}$ ** & $1.1(0.6)$ & $1.3(0.7)$ & - & - \\
\hline \multicolumn{5}{|c|}{$\begin{array}{l}\text { Note: SD = standard deviation, } \mathrm{TSH}=\text { thyroid stimulating hormone. } \\
\text { *Unless stated otherwise. } \\
\text { tAlcohol-related disorders such as alcoholism, alcoholic cirrhosis, alcoholic hepatitis and hepatic failure. } \\
\text { fTime between the date of a first-ever diagnosis of type } 2 \text { diabetes and cohort entry. } \\
\text { SLast measurement before cohort entry. } \\
\text { qIn the year before cohort entry. } \\
\text { **Among patients with available weight information. } \\
\text { †+Numbers less than } 5 \text { are not displayed, as per the confidentiality policies of the Clinical Practice Research Datalink. }\end{array}$} \\
\hline
\end{tabular}




\section{Results}

A total of 74300 patients who began receiving metformin or sulfonylurea monotherapy during the study period were included in the base cohort (Figure 1). Of those, 5689 were patients with treated hypothyroidism, and 59937 were euthyroid patients. The mean duration of antidiabetic treatment was 0.6 (standard deviation [SD] 0.8) years among patients with treated hypothyroidism and 1.1 (SD 1.3) years among euthyroid patients.

Table 1 presents the baseline characteristics of the patients. Overall, patients receiving metformin were younger, more likely to be obese and more likely to have used alcohol excessively. The mean baseline TSH levels between patients receiving metformin and sulfonylureas were similar within each subcohort.

The rates of TSH testing (tests/patient per year) during follow-up were similar between patients receiving metformin and sulfonylurea monotherapy, in both subcohorts. Among patients with treated hypothyroidism, the rate was $1.30(95 \% \mathrm{CI}$ $1.26-1.34$ ) tests per year in the metformin group and 1.23 (95\% CI 1.13-1.33) in the sulfonylurea group. Among euthyroid patients, the rate was 0.83 (95\% CI $0.83-0.84)$ in the metformin group and 0.76 (95\% CI 0.75-0.78) in the sulfonylurea group. At 1 year of follow-up, the mean TSH level was 2.31 (SD 2.49) $\mathrm{mIU} / \mathrm{L}$ in patients with treated hypothyroidism (metformin: 2.24 [SD 2.40] $\mathrm{mIU} / \mathrm{L}$; sulfonylureas: 2.82 [SD 3.03] mIU/L) and
2.03 (SD 1.16) mIU/L in euthyroid patients (metformin: 2.04 [SD 1.13] mIU/L; sulfonylureas: 2.02 [SD 1.40] $\mathrm{mIU} / \mathrm{L})$.

Among patients with treated hypothyroidism, there were 495 events of low TSH levels during follow-up, yielding an overall incidence rate of 119.7/1000 (95\% CI 109.4-130.7) person-years. Among euthyroid patients, there were 322 events of low TSH levels during follow-up, for an overall incidence rate of 4.5/1000 (95\% CI 4.0-5.0) person-years. Kaplan-Meier curves comparing patients receiving metformin and sulfonylurea monotherapy, stratified by subcohort, showed a higher cumulative incidence of low TSH levels in the metformin group than in the sulfonylurea group among patients with treated hypothyroidism, whereas no clear differences were observed among euthyroid patients (Appendix 1, supplemental figure 1).

Tables 2 and 3 present the results of the primary analysis for each subcohort. When compared with sulfonylurea monotherapy, the use of metformin monotherapy was associated with a $55 \%$ increased risk of low TSH levels in patients with treated hypothyroidism (adjusted HR 1.55, 95\% CI 1.09-2.20) (Table 2). In the first 90 days of use, the HR was elevated but not significant (adjusted HR 1.73, 95\% CI 0.90-3.34) (Table 2), followed by an increased risk after 90-180 days of use (adjusted HR 2.30, 95\% CI 1.00-5.29), which returned closer to the null after more than 180 days of use (adjusted HR

Table 2: Crude and adjusted hazard ratios for low thyroid-stimulating hormone levels $(<0.4 \mathrm{mIU} / \mathrm{L})$ associated with the use of metformin monotherapy, compared with sulfonylurea monotherapy, among 5689 patients with treated hypothyroidism and type 2 diabetes

\begin{tabular}{|c|c|c|c|c|c|}
\hline Variable & $\begin{array}{l}\text { No. events of } \\
\text { low TSH level }\end{array}$ & $\begin{array}{l}\text { Person-years } \\
\text { of exposure }\end{array}$ & $\begin{array}{c}\text { Incidence rate, per } 1000 \\
\text { person-years }(95 \% \mathrm{CI})\end{array}$ & Crude HR & Adjusted $\mathrm{HR}^{*}(95 \% \mathrm{Cl})$ \\
\hline Sulfonylurea, $n=762$ & 40 & 503 & $79.5 \quad(56.8-108.3)$ & 1.00 & 1.00 (reference) \\
\hline Metformin, $n=4927$ & 455 & 3633 & $125.2(114.0-137.3)$ & 1.60 & $1.55(1.09-2.20)$ \\
\hline \multicolumn{6}{|l|}{ Duration of uset } \\
\hline \multicolumn{6}{|l|}{$<90 \mathrm{~d}$} \\
\hline Metformin & 124 & 984 & $126.0(104.8-150.2)$ & 1.80 & $1.73(0.90-3.34)$ \\
\hline \multicolumn{6}{|l|}{$90-180 \mathrm{~d}$} \\
\hline Sulfonylurea & 6 & 88 & $68.2(25.0-148.4)$ & 1.00 & 1.00 (reference) \\
\hline Metformin & 99 & 619 & $159.9(130.0-194.7)$ & 2.34 & $2.30(1.00-5.29)$ \\
\hline $\begin{array}{l}\text { Note: } \mathrm{Cl}=\text { confidence inter } \\
{ }^{*} \text { Adjusted for age, sex, yea } \\
\text { alcoholic hepatitis and hep } \\
\text { tHazard ratios were estima }\end{array}$ & $\begin{array}{l}=\text { hazard ratio, TSI } \\
\text { ort entry, body ma } \\
\text { ure), hemoglobin } \\
\text { g time-dependent }\end{array}$ & $\begin{array}{l}\text { thyroid-stimulati } \\
\text { ndex, smoking, e } \\
\text { duration of diabe } \\
x \text { proportional } h\end{array}$ & $\begin{array}{l}\text { rmone. } \\
\text { ve alcohol use (i.e., alcohol-re } \\
\text { and use of lithium, amiodaron } \\
\text { s models. }\end{array}$ & $\begin{array}{l}\text { orders such } \\
\text { lucocorticoid }\end{array}$ & coholism, alcoholic cirrhosis, \\
\hline
\end{tabular}


1.29, 95\% CI 0.83-2.01). In euthyroid patients, the use of metformin was not associated with an increased risk of low TSH levels overall (adjusted HR 0.97, 95\% CI 0.69-1.36), with no clear pattern with duration of use (Table 3 ).

In a secondary analysis, the use of metformin monotherapy was not associated with an increased risk of suppressed TSH levels $(<0.1$ $\mathrm{mIU} / \mathrm{L}$ ) in patients with treated hypothyroidism (adjusted HR 0.99 , 95\% CI 0.57-1.72) or in euthyroid patients (adjusted HR 1.03, 95\% CI 0.52-2.03) (Table 4).

Overall, the sensitivity analyses yielded results that were consistent with those of the primary analysis (Appendix 1, supplemental tables 1-13).

\section{Interpretation}

Our findings support the hypothesis that metformin may lead to reductions in TSH levels in patients with treated hypothyroidism, ${ }^{4-7,22,23}$ with no effects in euthyroid patients. ${ }^{3,6,7}$ In the former group, we found that metformin monotherapy was associated with a $55 \%$ increased risk of low TSH levels $(0.4 \mathrm{mIU} / \mathrm{L})$, when compared with sulfonylurea monotherapy. This finding is concordant with the results of 3 previous studies. ${ }^{5-7}$ Furthermore, the risk appeared to be highest in the 90 to 180 days after treatment initiation (130\% increased risk), a finding that is also consistent with studies that observed TSH-lowering

Table 3: Crude and adjusted hazard ratios for low thyroid-stimulating hormone levels ( $<0.4 \mathrm{mIU} / \mathrm{L})$ associated with the use of metformin monotherapy, compared with sulfonylurea monotherapy, among 59937 euthyroid patients with type 2 diabetes

\begin{tabular}{|c|c|c|c|c|c|}
\hline Variable & $\begin{array}{l}\text { No. events of } \\
\text { low TSH level }\end{array}$ & $\begin{array}{l}\text { Person-years } \\
\text { of exposure }\end{array}$ & $\begin{array}{l}\text { Incidence rate, per } 1000 \\
\text { person-years }(95 \% \mathrm{CI})\end{array}$ & Crude HR & Adjusted HR* $(95 \% \mathrm{Cl})$ \\
\hline Sulfonylurea, $n=7980$ & 52 & 8576 & $6.1(4.5-8.0)$ & 1.00 & 1.00 (reference) \\
\hline Metformin, , $n=51957$ & 270 & 63047 & $4.3(3.8-4.8)$ & 0.71 & $0.97(0.69-1.36)$ \\
\hline \multicolumn{6}{|l|}{ Duration of uset } \\
\hline \multicolumn{6}{|l|}{$<90 d$} \\
\hline Sulfonylurea & 13 & 1666 & $7.8(4.2-13.3)$ & 1.00 & 1.00 (reference) \\
\hline Metformin & 49 & 11490 & $4.3(3.2-5.6)$ & 0.55 & $0.77(0.41-1.44)$ \\
\hline \multicolumn{6}{|l|}{$90-180 \mathrm{~d}$} \\
\hline Sulfonylurea & 6 & 1182 & $5.1(1.9-11.0)$ & 1.00 & 1.00 (reference) \\
\hline Metformin & 44 & 8310 & $5.3(3.8-7.1)$ & 1.04 & $1.45(0.61-3.47)$ \\
\hline \multicolumn{6}{|l|}{$>180 \mathrm{~d}$} \\
\hline Sulfonylurea & 33 & 5728 & $5.8(4.0-8.1)$ & 1.00 & 1.00 (reference) \\
\hline Metformin & 177 & 43248 & $4.1(3.5-4.7)$ & 0.72 & $0.96(0.64-1.44)$ \\
\hline
\end{tabular}

Table 4: Crude and adjusted hazard ratios for suppressed thyroid-stimulating hormone levels $(<0.1$ mIU/L) associated with the use metformin monotherapy, compared with sulfonylurea monotherapy, in patients with treated hypothyroidism or euthyroidism and type 2 diabetes

\begin{tabular}{|c|c|c|c|c|c|}
\hline Variable & $\begin{array}{c}\text { No. events of } \\
\text { suppressed TSH levels }\end{array}$ & $\begin{array}{l}\text { Person-years } \\
\text { of exposure }\end{array}$ & $\begin{array}{l}\text { Incidence rate, per } 1000 \\
\text { person-years }(95 \% \mathrm{Cl})\end{array}$ & Crude HR & $\begin{array}{l}\text { Adjusted HR* } \\
\qquad(95 \% \mathrm{Cl})\end{array}$ \\
\hline \multicolumn{6}{|c|}{ Patients with treated hypothyroidism, $n=5689$} \\
\hline Sulfonylurea, $n=762$ & 18 & 503 & $35.8(21.2-56.6)$ & 1.00 & 1.00 (reference) \\
\hline Metformin, $n=4927$ & 130 & 3633 & $35.8(29.9-42.5)$ & 1.05 & $0.99(0.57-1.72)$ \\
\hline \multicolumn{6}{|c|}{ Euthyroid patients, $n=59937$} \\
\hline Sulfonylurea , $n=7980$ & 12 & 8576 & $1.4(0.7-2.4)$ & 1.00 & 1.00 (reference) \\
\hline Metformin , $n=51957$ & 75 & 63047 & $1.2(0.9-1.5)$ & 0.85 & $1.03(0.52-2.03)$ \\
\hline
\end{tabular}


effects 3 months, ${ }^{5} 4$ months ${ }^{22}$ and 6 months ${ }^{23}$ after metformin initiation. There was no association with suppressed TSH levels $(<0.1 \mathrm{mIU} / \mathrm{L})$ among patients with treated hypothyroidism or euthyroidism. These results remained consistent after we performed several sensitivity analyses.

The biological mechanisms explaining the TSH-lowering properties of metformin are uncertain, and no unifying theory has been proposed thus far. ${ }^{24}$ Although metformin acts as an activator of adenosine $5^{\prime}$-monophosphateactivated kinase (AMPK) in the periphery, it has been shown to inhibit hypothalamic AMPK, ${ }^{25}$ which is involved in the regulation of the thyrotropin-releasing hormone-TSH axis. ${ }^{26}$ However, the exact mechanisms of how this central effect could lead to decreases in TSH levels remain to be elucidated. Others have proposed alternative mechanisms involving modification of thyroid hormone receptor affinity, thyroid hormone binding, bioavailability and metabolism, induced constitutive activation of the TSH receptor and interference with the TSH assay. ${ }^{24}$ A digestive interaction with levothyroxine is unlikely, given that metformin's TSH-lowering effect has also been described in patients with untreated hypothyroidism. ${ }^{7,23}$

The clinical consequences of low TSH levels induced by metformin need to be further investigated. In a recent study, 23 patients in whom low TSH levels developed while they were taking metformin did not exhibit the expected changes to heart rate and electrocardiographic parameters as patients with subclinical hyperthyroidism. ${ }^{27}$ However, the conclusions of this study are limited by its small sample and lack of adjustment for potential confounders. Given the relatively high incidence of low TSH levels observed in our study in patients receiving metformin (125.2/1000 person-years), there is a need for further research to determine the short- and longterm clinical consequences of this biochemical event, the necessity of monitoring TSH levels when starting metformin, and the appropriateness of adapting levothyroxine doses when low TSH levels are observed in patients starting metformin.

\section{Limitations}

The CPRD includes records of prescriptions written by general practitioners, but it is unknown whether patients adhered to the treatment. However, prescription renewals are likely good indicators of adherence. To our knowledge, TSH measurements have not been validated in the CPRD, although they are routine laboratory tests commonly ordered by general practitioners. It was not possible to assess the association between use of metformin and levels of thyroxine and triiodothyronine, because these tests were not routinely performed during the study period. Finally, residual confounding needs to be considered given the observational nature of the study, although consistent results were observed in sensitivity analyses.

\section{Conclusion}

The results of this longitudinal study confirmed that the use of metformin was associated with an increased risk of low TSH levels in patients with treated hypothyroidism, with the highest risk observed in the first 180 days after treatment initiation. Metformin appeared to have no effect on TSH levels in euthyroid patients. Given the relatively high incidence of low TSH levels in patients taking metformin, it is imperative that future studies assess the clinical consequences of this effect.

\section{References}

1. Stumvoll M, Nurjhan N, Perriello G, et al. Metabolic effects of metformin in non-insulin-dependent diabetes mellitus. $N$ Engl $J$ Med 1995;333:550-4.

2. Nathan DM, Buse JB, Davidson MB, et al. Medical management of hyperglycaemia in type 2 diabetes mellitus: a consensus algorithm for the initiation and adjustment of therapy. A consensus statement from the American Diabetes Association and the European Association for the Study of Diabetes. Diabetologia 2009;52:17-30.

3. Oleandri SE, Maccario M, Rossetto R, et al. Three-month treatment with metformin or dexfenfluramine does not modify the effects of diet on anthropometric and endocrine-metabolic parameters in abdominal obesity. J Endocrinol Invest 1999; 22:134-40.

4. Vigersky RA, Filmore-Nassar A, Glass AR. Thyrotropin suppression by metformin. J Clin Endocrinol Metab 2006;91:225-7.

5. Isidro ML, Penín MA, Nemiña R, et al. Metformin reduces thyrotropin levels in obese, diabetic women with primary hypothyroidism on thyroxine replacement therapy. Endocrine 2007;32:79-82.

6. Cappelli C, Rotondi M, Pirola I, et al. TSH-lowering effect of metformin in type 2 diabetic patients: differences between euthyroid, untreated hypothyroid, and euthyroid on L-T4 therapy patients. Diabetes Care 2009;32:1589-90.

7. Cappelli C, Rotondi M, Pirola I, et al. Thyreotropin levels in diabetic patients on metformin treatment. Eur J Endocrinol 2012; 167:261-5.

8. Díez JJ, Iglesias P. Relationship between serum thyrotropin concentrations and metformin therapy in euthyroid patients with type 2 diabetes. Clin Endocrinol (Oxf) 2013;78:505-11.

9. Casteràs $\mathrm{A}$, Zafon $\mathrm{C}$, Ciudin $\mathrm{A}$, et al. Are levothyroxine requirements lower in thyroidectomized diabetic patients on metformin treatment? Thyroid 2013;23:1510-3.

10. Biondi B, Wartofsky L. Treatment with thyroid hormone. Endocr Rev 2014;35:433-512.

11. Lupoli R, Di Minno A, Tortora A, et al. Effects of treatment with metformin on TSH levels: a meta-analysis of literature studies. J Clin Endocrinol Metab 2014;99:E143-8.

12. Herrett E, Thomas SL, Schoonen WM, et al. Validation and validity of diagnoses in the General Practice Research Database: a systematic review. Br J Clin Pharmacol 2010;69:4-14.

13. Khan NF, Harrison SE, Rose PW. Validity of diagnostic coding within the General Practice Research Database: a systematic review. Br J Gen Pract 2010;60:e128-36.

14. UK guidelines for the use of thyroid function tests. British Thyroid Association; 2006. Available: www.british-thyroid-association. org/info-for-patients/Docs/TFT_guideline_final_version_July_2006 .pdf (accessed 2014 July 23).

15. De Whalley P. Do abnormal thyroid stimulating hormone level values result in treatment changes? A study of patients on thyroxine in one general practice. Br J Gen Pract 1995;45:93-5.

16. Type 2 diabetes: the management of type 2 diabetes. London (UK): National Institute for Health and Clinical Excellence; 2009. Available: www.nice.org.uk/guidance/cg87 (accessed 2014 July 23). 
17. Haugen BR. Drugs that suppress TSH or cause central hypothyroidism. Best Pract Res Clin Endocrinol Metab 2009;23:793-800.

18. Schneeweiss S, Rassen JA, Glynn RJ, et al. High-dimensional propensity score adjustment in studies of treatment effects using health care claims data. Epidemiology 2009;20:512-22.

19. Hunton RB, Wells MV, Skipper EW. Hypothyroidism in diabetics treated with sulphonylurea. Lancet 1965;2:449-51.

20. Schless GL, Lee CT Jr. Oral hypoglycemic therapy and associated hypothyroidism. Ann N Y Acad Sci 1968;148:813-9.

21. Schneeweiss S, Patrick AR, Stürmer T, et al. Increasing levels of restriction in pharmacoepidemiologic database studies of elderly and comparison with randomized trial results. Med Care 2007; 45:S131-42.

22. Rotondi M, Cappelli C, Magri F, et al. Thyroidal effect of metformin treatment in patients with polycystic ovary syndrome. Clin Endocrinol (Oxf) 2011;75:378-81.

23. Morteza Taghavi S, Rokni H, Fatemi S. Metformin decreases thyrotropin in overweight women with polycystic ovarian syndrome and hypothyroidism. Diab Vasc Dis Res 2011;8:47-8.

24. Pappa T, Alevizaki M. Metformin and thyroid: an update. Eur Thyroid J. 2013;2:22-8

25. Chau-Van C, Gamba M, Salvi R, et al. Metformin inhibits adenosine $5^{\prime}$-monophosphate-activated kinase activation and prevents increases in neuropeptide $\mathrm{Y}$ expression in cultured hypothalamic neurons. Endocrinology 2007;148:507-11.

26. López M, Varela L, Vázquez MJ, et al. Hypothalamic AMPK and fatty acid metabolism mediate thyroid regulation of energy balance. Nat Med 2010;16:1001-8.

27. Cappelli C, Rotondi M, Pirola I, et al. Metformin-induced thyrotropin suppression is not associated with cardiac effects. Hormones (Athens) 2014;13:252-8

Affiliations: Centre for Clinical Epidemiology (Fournier, Yin, Yu, Azoulay), Lady Davis Institute, Jewish General Hospital; Department of Epidemiology, Biostatistics and Occupational Health (Fournier), McGill University; Division of Endocrinology (Yu), Jewish General Hospital; Department of Oncology (Azoulay), McGill University, Montréal, Que.

Contributors: Jean-Pascal Fournier, Oriana Yu and Laurent Azoulay contributed to the conception and design of the study. Laurent Azoulay contributed to the acquisition of data, which he, Jean-Pascal Fournier and Hui Yin analyzed and interpreted. Jean-Pascal Fournier drafted the article, which Hui Yin, Oriana Yu and Laurent Azoulay revised. All of the authors approved the version submitted for publication, and act as guarantors of the work.

Acknowledgement: Laurent Azoulay is the recipient of a Chercheur-Boursier award from the Fonds de la recherche du Québec - Santé.

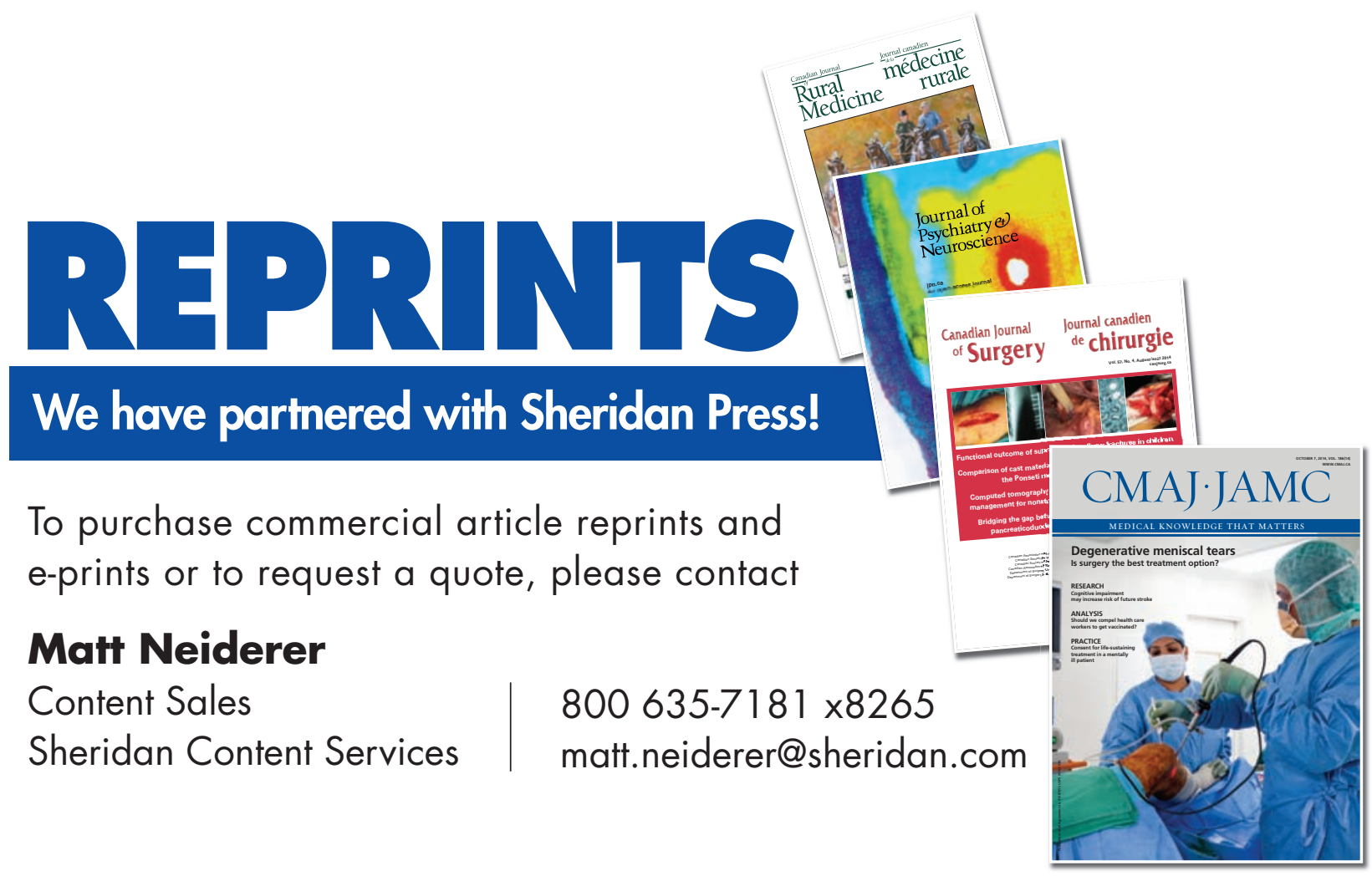

